\title{
A Study on Female Entrepreneurs in Malaysia
}

\section{Jennifer Hossain}

MBA, University of Kuala Lumpur, Malaysia; Lecturer, School of Business, Asian University of Bangladesh, Bangladesh

\section{Nadim Jahangir}

PhD, Australian Catholic University, Australia; Professor, Department of Management, Independent University, Bangladesh

\section{Md. Nur-Al-Ahad}

MBA, University Putra Malaysia, Malaysia; Master Student, Graduate School of Engineering, Toyohashi University of Technology, Japan

\begin{abstract}
This paper summarizes the impact of challenges within the scientific discussion on the issue of female entrepreneurship in Malaysia. In 67 countries of the world, approximately 126 millions of women have started a new business, and 98 millions of women are developing the already established businesses starting from 2012. However, the proportion of female entrepreneurs in general ranges from $1 \%$ to $40 \%$ in different countries around the world depending on the economic development, so the impact of women entrepreneurship on innovation and job creation is especially significant for developing countries, in particular for Malaysia. Throughout Malaysia's economic reforms, the small and medium business has played an important role in the growth of the economy of this country, the total number of Malaysian entrepreneurs is steadily increasing, and the government is implementing a significant number of entrepreneurship initiatives, although the number of women entrepreneurs in Malaysia is still lower than that of men entrepreneurs. The basis of the study was a highly structured method of deduction - the theoretical generalizations and the systematization of scientific developments of the researchers from different countries of the world formed the basis for the development of the hypothesis, and empirical studies were aimed at testing this hypothesis, explaining the causal relationships between the variables. The data for this study have been collected from a sample of 300 respondents, of which 120 are men, and 180 are women. The results of an empirical analysis of the survey data allowed to distinguish four main categories of factors that slow down the development of female entrepreneurship in Malaysia, namely resource, personal, economic, political, and cultural. Through the use of the regression analysis, the effect of all these factors (independent variables) on the growth of value added from the business carried out by the female entrepreneurs (dependent variable) was investigated in the article. The calculations showed that the correlation coefficient is 0.79 , and the determination coefficient is 0.62 . Testing the model for adequacy with t-statistics and p-value showed the significant impact of independent variables on the dependent one, which allows us to consider the proposed hypothesis to be confirmed. The results of the research can be useful for government officials, local authorities and entrepreneurs, not only in Malaysia but also in other countries.
\end{abstract}

Keywords: entrepreneurship, entrepreneurs, female entrepreneurs, Malaysia, challenges for female entrepreneurs.

JEL Classification: M10, L26, J16.

(C) The Authors, 2018. This article is published with open access at Sumy State University.

\section{Introduction}

Research has found that there is a link between entrepreneurship and economic process. Entrepreneurship has been particularly crucial for developing economies like Malaysia. Especially, throughout the time of Malaysian economic reforms, each small and medium-sized enterprises (SMEs) have played a big role in the country's growth.

In 67 countries globally as of 2012, approximately 126 million women were starting or running new businesses and 98 million were running already established businesses (Babson, 2016). However, the rate of females engaged in entrepreneurship varies from $1 \%$ to $40 \%$ globally. Thus, women entrepreneurs' impact on innovation and job creation differs worldwide (Kelley, 2013). Research indicates the trend for increased female entrepreneurship in the future, moving women closer to their male counterparts. Moreover, female 
entrepreneurs are predicted to continue to match the changing situation in terms of more gender equality in business environments and in the society (Zhang \& Alon, 2010).

Since the number of female entrepreneurs in Malaysia is increasing, hence it is interesting to see how the females are making their way into the world of entrepreneurship. There are some set challenges, which females have to face when making their way into the world of entrepreneurship.

In Malaysia, females involve numerous administrative positions, while because of new companies, male overwhelm (Flannery, 2013). It has been discovered just $20 \%$ of all business visionaries in Malaysia are female (Teoh and Chong, 2014). Potential purposes behind this low rate of female business people are believed to be identified with culture and financing specialists' inclinations (Flannery, 2013). Additionally, it has likewise been discovered that regardless of Malaysia's development and that the part of women is changing, Malaysian women confront abnormal amounts of disparities in business, informal communities, training, and capital access.

Even though some research indicates that there are no significant gender differences in entrepreneurship, many of the above-mentioned obstacles for female entrepreneurs have been found in the case of Malaysia. It is interesting to observe the challenges and differences that exist between male and female entrepreneurs in Malaysia. Hence, the overall objective of this study has been circled around this theme.

\section{Literature Review}

\section{Entrepreneurship}

As a scholastic discipline, entrepreneurship has made some amazing progress in its 300 long years of presence. Numerous hypotheses have gone back and forth, numerous models and understandings have been proposed, of which some have been acknowledged, some rejected (Bjerke, 2010). The term entrepreneurship is set apart by an extensive variety of existing definitions in the writing. In both advanced and developing economies, entrepreneurship is one of the real drivers of the economy (Ramadani and Hisrich, 2015).

According to Shane (2003), entrepreneurship means to discover, evaluate and exploit opportunities with the purpose of introducing new goods and services, processes or a completely new market.

Timmons (1999) defines entrepreneurship as a way of thinking, reasoning, and acting that is opportunity obsessed, holistic in approach, and leadership balanced. Coulter (2001) says that entrepreneurship is 'the process whereby an individual or a group of individuals use organized efforts and means to peruse opportunities to create value and grow by fulfilling wants and needs through innovation and uniqueness, no matter what resources are currently controlled'. Kuratko and Hodgetts (2004) perceive entrepreneurship as 'a dynamic process of vision, change, and creation'.

\section{Male and Female Entrepreneurship}

Both women and men are running businesses in all sectors all around Malaysia. Most businesses in Malaysia are small. There are some interesting facts about the field of entrepreneurship in Malaysia. There is a growing trend among entrepreneurs to get higher education and people who have higher education usually start enterprises in the current scenario. A higher educational number has increased by several percents during a decade, which is reflected positively in entrepreneurial activities. In recent years, one more point to be noted here is that more women have higher education than men do. The participation of women in entrepreneurship varies around the globe and thus their impact on innovation and job creation. If females are not engaged as entrepreneurs, the capacity of half the world's population in terms of job creation is lost (Kelley, Brush \& Greene, 2012).

\section{Challenges for Malaysian Entrepreneurs}

Developing countries face different challenges in terms of entrepreneurship and small and medium enterprises compared to the developed countries. In developing or transforming countries, integrated finance or factor markets are still incomplete and they often lack political stability (Dolles \& Babo, 2003). Findings of entrepreneurial challenges generally in developing countries include unstable and highly bureaucratic business environments, complicated business registrations and taxation systems, poorly designed and enforced the contract and property laws, inadequate infrastructure, poor policies, limited access to capital, corruption and lack of managerial experiences (Moghavvemi \& Salleh, 2014). 
In Malaysia, weaknesses in institutions hinder development hence; the setup of private firms prompts entrepreneurs to form political connections in order to increase their chances to succeed. The environment of Malaysian institutions differs greatly from that of the Western countries, with a very strong Asian culture.

\section{Challenges for Female Entrepreneurs}

In societies, men do little or no unpaid household work. However, females are expected to put time for their unpaid household chore work. As a result, female entrepreneurs have a lack of quality time to put into their new ventures. Another problem may be the unawareness of the particular constraints faced by female entrepreneurs (and female workers in general) that is long-standing cultural norms biased against women may seem 'natural' in the society and such unpaid household work may thus not be perceived as discriminatory (Teoh \& Chong, 2014).

\section{Objectives of the Study}

The main objective of the study is to find out the impact of challenges on female entrepreneurship in Malaysia. The specific objectives of the study are:

Objective 1: To find out the impact of resource challenges on female entrepreneurship in Malaysia.

Objective 2: To find out the impact of personal challenges on female entrepreneurship in Malaysia.

Objective 3: To find out the impact of an economic and political challenge on female entrepreneurship in Malaysia.

Objective 4: To find out the impact of cultural challenges on female entrepreneurship in Malaysia.

\section{Data and Methodology}

For this study, a deductive approach has been utilized. The deductive approach can be defined as the approach where the theory is used to develop a hypothesis and design a research strategy to test the hypothesis. The deductive approach puts emphasis on scientific principles; moving from theory to data; the need to explain causal relationships between variables; the collection of quantitative data; the application of controls to ensure the validity of data; a highly structured approach etc. Quantitative research strategy has been utilized for this study. The purpose of this strategy is to analyze the collected primary data, perform statistical or other analytical means, and reach to a reliable and valid conclusion. Primary data has been utilized for this study. Primary data have been collected through the means of a questionnaire.

\section{Results and Discussion}

The total sample size for this study is 300 . Since the sample size is in handsome amount, hence a sample profile will give a clear idea of the chosen samples.

Following is a Table 1 showing the sample profile for this study.

Table 1. Sample Profile

\begin{tabular}{|lc|}
\hline \multicolumn{1}{|c|}{ Sample Profile Facts } & \\
\hline Total respondent & 300 \\
\hline Male & 120 \\
\hline Female & 180 \\
\hline
\end{tabular}

Since the main objective of this study is to measure the impact of challenges on the female entrepreneurship, hence, the impact of challenges is the independent variable and female entrepreneurship is the dependent variables. Following is the regression equation showing this - Impact of Challenges (Resource Challenges, Personal Challenges, Economic and Political Challenges, Cultural Challenges) $=$ (Female Entrepreneurship in Malaysia). Women face many problems when they opt for establishing a new business. Having studied the previous literature and prudent thinking, it is quite evident that females in Malaysia face myriad challenges when they go for entrepreneurship. Since the challenges are many and varied in nature, hence they have been grouped into four main categories here. The four main categories of challenges are resource challenges, personal challenges, economic and political challenges, and finally cultural challenges.

Resources are the input for the entrepreneurship. Females in Malaysia usually feel the challenge of resources when they go for establishing a new business. There are three main resource challenges faced by the female entrepreneurs in Malaysia namely information resources, financial resource and human resources. The information resource challenge is the first challenge usually faced by all potential female entrepreneurs in 
Malaysia. In the marketplace, there is information asymmetry meaning entrepreneurs, particularly female entrepreneurs usually do not get all the necessary information needed for establishing the business. Information in today's world is the vital resource. In today's hypercompetitive marketplace, success can only be assured with the usage of information. Right information for right strategy - this has become secret sauce for today's high profile businesses. Finance is the lifeblood of the businesses. Finance is highly required for running any business smoothly. Managing the financial resources for a start-up is a crucial stage for any entrepreneurs' particularly female entrepreneurs in Malaysia. The financial market is highly regulated and has a less scope of opportunities for female entrepreneurs. Recently things have started to change with the initiatives taken by the government and the joint effort of the financial institutions in Malaysia. The resource challenge faced by the female entrepreneurs in Malaysia is the challenge of human resources. Efficient human resources are required for running the start-up or new business smoothly but in Malaysia, there is a potential lack of human resources with an utmost interest for having the career with a start-up. Hence, entrepreneurs' particularly female entrepreneurs in Malaysia face this challenge of human resources.

The second category of challenges faced by female entrepreneurs is personal challenges. Entrepreneurs like others are human beings and they have similar personal shortcomings like others. The degree of personal challenges is more intense for female entrepreneurs compared with male entrepreneurs in Malaysia. Being in a male-dominated society, females are always expected to perform some specific tasks and roles. The matter of entrepreneurship is usually seen as an outside duty and often optional after these specific tasks. In this situation, it is quite challenging for the females in Malaysia to fulfill their personal obligations and then go for having a business of their own.

Economic and politics are interconnected and they have a usual role to play in the smooth operation of any business be it established business or a start-up. The economic condition of any country affects the proper operation of any business entity. A good and favorable economic condition is highly instrumental for the success of any business entity. This is more crucial for start-ups. Economic conditions are usually part of the macro-environment of business. In Malaysia, the economic condition is quite stable and it has been improving for the last couple of years. The inflation rate is always in checked condition. The financial market in Malaysia is also highly regulated. All these have ensured a favorable economic condition, which is highly required for the smooth operation and success of any business entity. Then there is the impact of the political condition. The political condition of any country affects the business eco-system directly. A stable political condition has helped developed and industrialized nations around the world to flourish. In Malaysia, the political condition is stable and this is highly beneficial for any start-up. Together, economic and political challenges have important implications for female entrepreneurs in Malaysia. A good economic condition is highly required for the female entrepreneurs in Malaysia. On the other hand, a stable political condition and favorable policies to foster female entrepreneurship in Malaysia are highly expected.

Cultural challenge is the last challenge faced by the female entrepreneurs in Malaysia. In Malaysia, the society is predominantly male-oriented. So, the concept of female entrepreneurship is not always welcomed. Besides, the cultural mindset is to see females to perform household tasks and taking care of household things. However, things have started to change recently with a large pool of females joining the workforce and the successful running of businesses by females in Malaysia.

All these challenges described have been taken as independent variables in this study. The only dependent variable is female entrepreneurship in Malaysia. This essentially means that if these challenges can be properly addressed, then the success of female entrepreneurship in Malaysia can be ensured with a high degree of confidence.

With the model mentioned, regression analysis has been performed. Table 2 shows the descriptive statistics.

Table 2. Descriptive Statistics

\begin{tabular}{|l|c|c|}
\hline \multicolumn{1}{|c|}{ Variables } & Mean & Std. Deviation \\
\hline Dependent Variables: & & \\
Resource Challenges & 1.66 & 0.20 \\
Personal Challenges & 1.60 & 0.30 \\
Economic and Political Challenges & 1.50 & 0.10 \\
Cultural Challenges & 1.40 & 0.23 \\
\hline Independent Variable: & & \\
Female Entrepreneurship in Malaysia & 4.48 & 1.19 \\
\hline
\end{tabular}


From the above table, the mean value for the dependent variables is 1.66, 1.60, 1.50 and 1.40. The standard deviation values for the dependent variable suggest the data is distributed near to the mean value.

The mean value for female entrepreneurship in Malaysia is 4.48 while the standard deviation is 1.19. Correlation measures the strength and direction of the linear relationship between the two variables. The correlation coefficient can range from -1 to +1 , with -1 indicating a perfect negative correlation, +1 indicating a perfect positive correlation, and 0 indicating no correlation at all. (A variable correlated with itself will always have a correlation coefficient of 1). This correlation is also known as "Pearson's Correlation".

A pairwise correlation matrix of the variables has been provided in the following Table 3.

Table 3. Pairwise Correlation

\begin{tabular}{|l|c|c|}
\hline \multicolumn{1}{|c|}{ Variables } & Challenges & Female Entrepreneurship \\
\hline Challenges & 1.000 & \\
\hline Female Entrepreneurship & 0.89 & 1.000 \\
\hline
\end{tabular}

From the above table, it is evident that there are different degrees of correlations among the variables used in the study. Correlation defines the relationship among the different variables used in the study. All the variables have a perfect positive correlation with itself.

\section{Regression Analysis}

Since there is a regression equation for this study, hence performing the regression analysis gives a total purview of the exactness of the equation.

Taking female entrepreneurship as the dependent variable and performing the regression analysis yield the following result.

Table 4. Regression Output

\begin{tabular}{|c|c|}
\hline $\mathbf{R}$ & R Square \\
\hline 0.79 & 0.62 \\
\hline
\end{tabular}

Here, the value of $\mathrm{R}$ represents the simple correlation and it is 0.79 , which indicates a moderate high degree of positive correlation.

\section{Significance of the Model}

For the regression model to be valid $99 \%$ reliable, test of reliability has been performed. The values of t-statistic and p-value signify the validity and reliability of this model. Following is a Table 5 showing this.

Table 5. Test of Significance

\begin{tabular}{|l|c|c|}
\hline \multicolumn{1}{|c|}{ Model } & t & Sig. \\
\hline Challenges & 8.61 & 0.026 \\
\hline Female Entrepreneurship in Malaysia & 7.17 & 0.012 \\
\hline
\end{tabular}

As a generally accepted statistical rule, any model is significant if its p-value is less than 0.05 for the twotailed test. From the analysis, a significant positive relationship has been found.

\section{Conclusion and Findings}

\section{Research Design}

Entrepreneurship has been a topic of research for many studies. Sadly, there is a less significant number of studies looking into the matter of female entrepreneurship. There is also a lesser number of studies available for female entrepreneurship in the developing countries around the world.

Malaysia is one of the most promising countries in today's world. In Malaysia, the number of entrepreneurs is on increase. Of them, the participation of female entrepreneurs is the most striking one.

Although there are studies available discussing entrepreneurship, there is less number of significant studies exploring the challenges faced by female entrepreneurs in Malaysia. In this study, the challenges faced by female entrepreneurs have been studied in Malaysian context. This study contributes to the existing literature as empirical evidence for further research. Since businesses, nowadays-entrepreneurial initiatives are becoming more famous; hence, it will be more beneficial for the coming as well as existing entrepreneurs. The study has added a new dimension to the previous findings since this study is of a new nature in the Malaysian context. 


\section{The First Objective}

The first objective of this study has been set up to find out the impact of resource challenges on female entrepreneurship in Malaysia. In order to realize the objective, data have been collected in the organized matter and analysed systematically. Based on the results obtained, it is visible that female entrepreneurs in Malaysia face some definite set of resource challenges.

\section{The Second Objective}

The second objective of this study has been set up to find out the impact of personal challenges on female entrepreneurship in Malaysia. The analysis shows that females in Malaysia usually face myriad personal challenges when they opt for having their own business. These challenges usually act as a barrier for the flourishment of female entrepreneurship in Malaysia.

\section{The Third Objective}

The third objective of this study has been set up to find out the impact of economic and political challenges on female entrepreneurship in Malaysia. The analysis shows that females in Malaysia face several degrees of economic and political challenges when they opt for starting a venture.

\section{The Fourth Objective}

The fourth and final objective of this study has been set up to find out the impact of cultural challenges on female entrepreneurship in Malaysia. From the analysis, it is evident that cultural dimensions affect the environment for female entrepreneurship in Malaysia.

\section{Implications of Findings}

This study contributes to the existing literature as empirical evidence for further research. Since entrepreneurial initiatives are becoming more famous nowadays; hence, it will be more beneficial for the potential as well as existing entrepreneurs' particularly female entrepreneurs. The study has added a new dimension to the previous findings since this study is of a new nature in Malaysian context.

\section{Recommendation for Future Research}

The study has several limitations, which suggest the implications for further research. One of the limitations of this study is the context to which the study can be generalized to the wider population of small business. Future researchers may improve the results of the study by increasing the sample size. Furthermore, it could be good to include samples from more than one country in order to remove the systematic risk of investigating only one particular country.

\section{References}

1. Bates, T. (2002). Restricted access to markets characterizes women-owned businesses. Journal of Business Venturing, 17(4), 313-324. http://dx.doi.org/10.1016/s0883-9026 (00)00066-5.

2. Bjerke, B. (2010). Entrepreneurship, space, and place. Book, pp. 50-60.

3. College, B. (2016). Reports | Global Entrepreneurship Monitor | Babson College. Babson.edu. Retrieved 2 March 2016. Retrieved from http://www.babson.edu/Academics/centers/blank-center/globalresearch/gem/pages/reports.aspx.

4. Coulter, M. (2001). Entrepreneurship in action. Upper Saddle River, N.J.: Prentice Hall.

5. Dolles, H., and Babo, M. (2003). The development of Entrepreneurship in Transitional Economies: The Perspective of Chinese and South African Entrepreneurs, Working paper: Deutsches Institut für Japanstudien. Vol. 20.

6. Flannery, R. (2015). Forbes Welcome. Forbes.com. Retrieved 2 April 2016. Retrieved from http://www.forbes.com/sites/russellflannery/2013/04/04/solitary-woman/.

7. Johnson, P. \& Clark, M. (2006). Business and management research methodologies. London: SAGE.

8. Kelley, D.J., Brush, C.G., Greene, P.G., \& Litovsky, Y. (2013). Global Entrepreneurship Monitor: 2012 Women's Report. Boston: The Center for Women's Leadership at Babson College and London Business School.

9. Kitching, B. \& Jackson, P. (2002). Female entrepreneurs in a transitional economy: Businesswomen in China. The International Journal of Entrepreneurship and Innovation, 3(2), 145-155. Available at: http://dx.doi.org/10.5367/000000002101299132.

10.Kuratko, D. \& Hodgetts, R. (2004). Entrepreneurship. Mason, Ohio: Thomson/South-Western.

11.Low, M. (1988). Entrepreneurship: Past Research and Future Challenges. Journal of Management, 14(2), 
139-161. Available at: http://dx.doi.org/10.1177/014920638801400202.

12.Ming Yen Teoh, W. \& Choy Chong, S. (2014). Towards strengthening the development of women entrepreneurship in Malaysia. Gender in Mgmt: Int J, 29(7), 432-453. Available at: http://dx.doi.org/10.1108/gm-10-2013-0122.

13.Moghavvemi, S. \& Akma Mohd Salleh, N. (2014). Malaysian entrepreneurs' propensity to use IT innovation. Journal of Ent. Info Management, 27(2), 139-157. Available at: http://dx.doi.org/10.1108/jeim05-2012-0026.

14.Muravyev, A., Talavera, O., \& Schäfer, D. (2009). Entrepreneurs' gender and financial constraints: Evidence from international data. Journal of Comparative Economics, 37(2), 270-286. Available at: http://dx.doi.org/10.1016/j.jce.2008.12.001.

15.Ramadani, V., Hisrich, R.D., Gerguri, S. (2015). Female entrepreneurs in transition economies: Insights from Albania, Macedonia and Kosovo. World Review and Entrepreneurship, Management and Sustainable Development, 11(4), 391-413.

16.Saunders, M., Lewis, P., \& Thornhill, A. (2003). Research methods for business students. Harlow, England: Prentice Hall.

17.Shane, S. (2003). A general theory of entrepreneurship. Cheltenham, UK: E. Elgar.

18.Timmons, J. (1999). New venture creation. Boston: Irwin/McGraw-Hill. 